\title{
Efeitos da suplementação das vitaminas C e E na prática de atividade física: uma revisão sistemática
}

\author{
Effects of supplementation of vitamins $C$ and $E$ in the practice of physical activity: a \\ systematic review
}
Efectos de la suplementación de las vitaminas C y E en la práctica de actividad física: una revisión sistemática

Tamires da Cunha Soares ${ }^{1 *}$, Maria de Fatima Sousa Barros Vilarinho ${ }^{1}$, Ticianne da Cunha Soares ${ }^{2}$, Lívia de Araújo Rocha1, Luana Carla Braga Santana ${ }^{2}$, Liriane Andressa Alves da Silva ${ }^{1}$, Ravena Kelly da Cruz Farias ${ }^{1}$, Neyeli Cristine da Silva ${ }^{1}$, Milena Maria de Carvalho Sousa ${ }^{1}$, Karlos Heitor Rodrigues Silva ${ }^{3}$, Gabriel Barbosa Câmara ${ }^{4}$, Vanessa Moreira de Lima1, Igor Sabino Barros ${ }^{1}$, Gilvania da Conceição Rocha ${ }^{5}$, Victor Alves de Oliveira ${ }^{5}$.

\section{RESUMO}

Objetivo: Realizar uma revisão sistemática sobre os efeitos da suplementação das vitaminas $C$ e $E$, em praticantes de atividade física, sejam amadores ou profissionais. Métodos: A busca bibliográfica ocorreu nas bases de dados, PubMed e Scielo, e na Biblioteca Virtual em Saúde, utilizando-se os descritores em saúde "vitamina C", "vitamina E", "antioxidante" e "atividade física", combinados entre si, assim como seus termos correspondentes nas línguas inglesa. Foram selecionados 8 artigos que versavam sobre pesquisas experimentais. Resultados: A suplementação das vitaminas $C$ e E mostrou reduzir a peroxidação lipídica, dano muscular, resposta inflamatória e hemólise, além de melhorar o quadro de asma induzido pelo exercício. Por outro lado, efeitos positivos não foram percebidos sobre a sensibilidade à insulina, parâmetros de performance e adaptação ao exercício de endurance. Considerações finais: A ingestão de antioxidantes pode inibir a resposta adaptativa advinda da elevação fisiológica de espécies reativas de oxigênio em decorrência do exercício físico, isto pode ser benéfico ou não. A suplementação com fim de melhora da performance e resistência ao exercício não encontrou fundamentação neste recorte amostral, porém, análises futuras devem ser realizadas.

Palavras-chave: Ácido ascórbico, Alfa-tocoferol, Exercício, Suplementos nutricionais.

\section{ABSTRACT}

Objective: To carry out a systematic review on the effects of vitamin $C$ and $E$ supplementation on physical activity practitioners, whether amateur or professional. Methods: The bibliographic search was carried out in the databases, PubMed and Scielo, and in the Virtual Health Library, using the descriptors in health "vitamin C", "vitamin E", "antioxidant" and "physical activity", combined between as well as their corresponding terms in English. We selected 8 articles that dealt with experimental research. Results: Vitamin C and E supplementation has been shown to reduce lipid peroxidation, muscle damage, inflammatory response and hemolysis, and improve exercise-induced asthma. On the other hand, positive effects were not perceived on insulin sensitivity, performance parameters and adaptation to endurance exercise. Final considerations: Intake of antioxidants may inhibit the adaptive response from the physiological elevation of reactive oxygen species due to physical exercise, this may be beneficial or not. Supplementation with the aim of improving performance and resistance to exercise did not find grounds for this sample, but future analyzes should be carried out.

Keywords: Ascorbic acid, Alpha-tocopherol, Exercise, Dietary supplements.

${ }^{1}$ Graduação em Nutrição pela Universidade Federal do Piauí, Picos, Piauí.

* E-mail: tamiressoaresnutri@outlook.com

${ }^{2}$ Graduação em Enfermagem pela Universidade Federal do Piauí, Picos, Piauí.

${ }^{3}$ Graduação em Farmácia pela Faculdade de Ensino Superior de Floriano, Floriano, Piauí.

${ }^{4}$ Graduação em Nutrição pela Faculdade de Ciências Médicas de Campina Grande, Campina Grande,

Paraíba.

${ }^{5}$ Discente do Departamento de Nutrição da Universidade Federal do Piauí, Picos, Piauí. 


\section{RESUMEN}

Objetivo: Realizar una revisión sistemática sobre los efectos de la suplementación de las vitaminas $\mathrm{C}$ y $\mathrm{E}$, en practicantes de actividad física, sean aficionados o profesionales. Métodos: se utilizaron los descriptores en salud "vitamina C", "vitamina E", "antioxidante" y "actividad física", combinados entre sí, así como sus términos correspondientes en las lenguas inglesa para la búsqueda bibliográfica en las bases de datos, PubMed, Scielo y Biblioteca Virtual en Salud. Se seleccionaron 8 artículos que versaban sobre investigaciones experimentales. Resultados: La suplementación de las vitaminas C y E mostró reducir la peroxidación lipídica, daño muscular, respuesta inflamatoria y hemólisis, además de mejorar el cuadro de asma inducido por el ejercicio. Por otro lado, los efectos positivos no se percibían sobre la sensibilidad a la insulina, los parámetros de rendimiento y la adaptación al ejercicio de resistencia. Consideraciones finales: La ingesta de antioxidantes puede inhibir la respuesta adaptativa proveniente de la elevación fisiológica de las especies reactivas de oxígeno como consecuencia del ejercicio físico, esto puede ser benéfico o no. La suplementación con fin de mejora de la performance y resistencia al ejercicio no encontró fundamentación en este recorte muestral, sin embargo, análisis futuros deben ser realizados.

Palabras clave: Ácido ascórbico, Alfa-tocoferol, Ejercicio, Suplementos dietéticos.

\section{INTRODUÇÃO}

No ranking mundial do mercado de academias, o Brasil é o segundo maior país no que diz respeito ao número de unidades em funcionamento, ficando atrás apenas dos Estados Unidos. Isto demonstra que os brasileiros estão cada vez mais preocupados e comprometidos com a saúde corporal (CONFEF, 2015). É imprescindível que o praticante de atividade física tenha suas necessidades nutricionais atendidas, visto que há uma relação direta entre alimentação, desempenho e eficiência da prática de exercícios físicos (JEUKENDRUP, 2017).

Neste cenário, sabe-se que a boa alimentação deve ser o ponto de partida para o melhor aproveitamento das atividades realizadas. Os nutrientes fornecidos serão utilizados na forma de energia, reparação de tecidual, fortalecimento do sistema imunológico, formação de enzimas e proteção contra elevações demasiadas dos radicais livres, culminando na melhora do desempenho geral. Hábitos alimentares equilibrados e ajustados às necessidades individuais, são cuidados suficientes para praticantes de exercícios físicos sem fins competitivos, sendo dispensável o uso de suplementos e outras estratégias para o desenvolvimento corporal (SOUZA e CARGNIN-CARVALHO, 2018; MACHADO-MOREIRA et al. 2006).

Por outro lado, atletas de alto rendimento necessitam de um aporte energético consideravelmente maior quando comparado a praticantes amadores. Entre atletas, o valor da necessidade energética pode variar de 3000 a $5000 \mathrm{kcal}$ por dia, dificultando o alcance desta meta apenas com a ingestão de alimentos (CAPRIO, et al, 2018). Além disso, outros aspectos peculiares do metabolismo de atletas profissionais, propiciam a busca por recursos que melhorem a imunidade, performance e rendimento físico, tornando o uso de suplementos, uma prática comum neste meio (MATOS; LIBERALLI, 2008; FAYH, et al., 2013; BENNEMAN, et al., 2018). Tendo em vista isso, os suplementos alimentares são recursos utilizados com o objetivo de suprir necessidades metabólicas em casos específicos como este. Tais produtos, por definição, devem conter um ou mais dos seguintes nutrientes: aminoácidos, metabólicos, constituintes, extratos, ervas ou botânicos, minerais e vitaminas (BRASIL, 2006; HALLAK, et al., 2007).

As vitaminas não são fontes de energia para os exercícios, mas têm participação importante nos processos metabólicos, especialmente na regulação das reações químicas de produção de energia, de síntese de substâncias e estruturas vitais (enzimas, hormônios etc.) e degradação de compostos, sendo classificadas como substâncias ou compostos reguladores. Ademais, estes compostos atuam como agentes antioxidantes, ou seja, inibem a ação de $s$ atuando como agentes protetivos das células e estruturas afins (VIEBIG; NACIF, 2010).

As vitaminas C (ácido ascórbico) e E ( $\alpha$-tocoferol) são micronutrientes antioxidantes comumente encontrados na alimentação usual, cujas recomendações dietéticas variam de acordo com a idade, sexo, lactação e outros fatores. O ácido ascórbico é uma vitamina hidrossolúvel que atua como cofator em diversas 
reações químicas reduzindo espécies reativas de oxigênio (EROs), estando presente na composição de frutas e vegetais, como acerola, caju, kiwi, laranja, morango, limão, dentre outras. O $\alpha$-tocoferol, por sua vez, é um nutriente lipossolúvel com forte função antioxidante, contido nas carnes, ovos, óleos, manteigas, nozes e amêndoas (INSTITUTE OF MEDICINE, 2000).

Apesar do fácil acesso a estes nutrientes pela via alimentar, a suplementação dos mesmos é uma prática frequente na atividade física amadora ou profissional. A principal motivação para tal é que a adição destas vitaminas sobre o consumo dietético tem demonstrado proteger o organismo do dano oxidativo causado pelo exercício físico extenuante. Além disso, a literatura tem evidenciado que a ingestão dos dois nutrientes, produz resultados sinérgicos e complementares, uma vez que o ácido ascórbico pode reciclar a vitamina $\mathrm{E}$ degradada, elevando o potencial antioxidante destes micronutrientes (CHOU, et al., 2018).

O estudo da ação antioxidante de vitaminas na prática da atividade física tem gerado importantes discussões no âmbito da nutrição esportiva, uma vez que estes nutrientes desempenham papel inibidor de EROs. A produção excessiva de EROs provenientes das atividade anaeróbias ou aeróbias de média à alta intenssidade, pode causar efeito deletério em células e estruturas celulares, podendo repercutir em déficits metabólicos, comprometimento do sistema imune, fadiga e lesões musculares (VIEBIG; NACIF, 2010; MENDES; TIRAPEGUI, 2012). Entretanto, a liberação de EROs induzida pelo exercício pode funcionar como ativadores do sistema antioxidante fisiológico, induzindo adaptações biológicas benéficas ao treinamento. Este achado coloca em dúvida a necessidade e efetividade da suplementação de vitaminas, para além do aporte dietético usual (MANKOWSKI, et al.; 2015; CRUZAT, et al., 2014).

Diante disso, esta revisão teve como objetivo reunir e discutir as evidências científicas sobre os efeitos da suplementação combinada das vitaminas $\mathrm{C}$ e E, em praticantes amadores ou profissionais de atividade física.

\section{METODOLOGIA}

Trata-se de uma revisão sistemática da literatura, com busca dos artigos nas bases eletrônicas de dados Scielo e Pubmed, e na Biblioteca Virtual de Saúde (BVS). Os descritores utilizados para a pesquisa foram selecionados mediante consulta ao DECS (Descritores de assuntos em ciências da saúde da BIREME), sendo eles "vitamina C", "vitamina E", "antioxidante" e "atividade física", além de seus termos correspondentes na língua inglesa. Os termos foram inseridos em formulário avançado, combinados entre si.

Foram incluídos todos os artigos originais, escritos nas línguas portuguesa, inglesa e espanhola, indexados no período de janeiro de 2007 à junho de 2018, disponíveis em formato de texto completo, realizados em humanos, que tratassem da avaliação dos efeitos da ingestão das vitaminas $C$ e $E$, combinadas entre si, em forma de suplementação oral, no contexto de atividade física. Quanto ao desenho metodológico dos estudos, foram considerados os tipos transversal ou longitudinal, duplo-cego, placebo-controlado, ensaio clínico e caso controle. Os filtros de idioma, disponibilidade de texto completo, ano de publicação e formato de trabalho (artigo), foram assinaladas nas bases de dados, quando esta opção esteve disponível.

Os critérios de exclusão englobaram metodologias desenvolvidas em animais, artigos disponíveis em outros idiomas que não os elegidos, trabalhos indisponíveis na íntegra, referências duplicadas e/ou que não atendessem aos critérios de inclusão pré-estabelecidos.

Os artigos encontrados foram inicialmente avaliados quanto ao título, afim de se perceber qual o objeto da pesquisa. Posteriormente, os trabalhos remanescentes tiveram seus resumos analisados para se verificar qual o objetivo e metodologia da pesquisa. Finalmente, os artigos que restaram foram lidos e analisados na íntegra, para rever a adequação aos critérios de inclusão e exclusão acima citados. A leitura na íntegra se faz necessária para rever todos os pontos anteriores, garantindo que os artigos escolhidos estejam em simetria com o objetivo geral da revisão. No caso do presente estudo, foram excluídos 18 artigos nesta última fase, pois apesar de terem sido aprovados quanto ao título e resumo, estes não se adequaram aos critérios de inclusão definidos nesta pesquisa. Estes processos podem ser visualizados na Figura 1. 
Figura 1. Processos de seleção dos artigos.

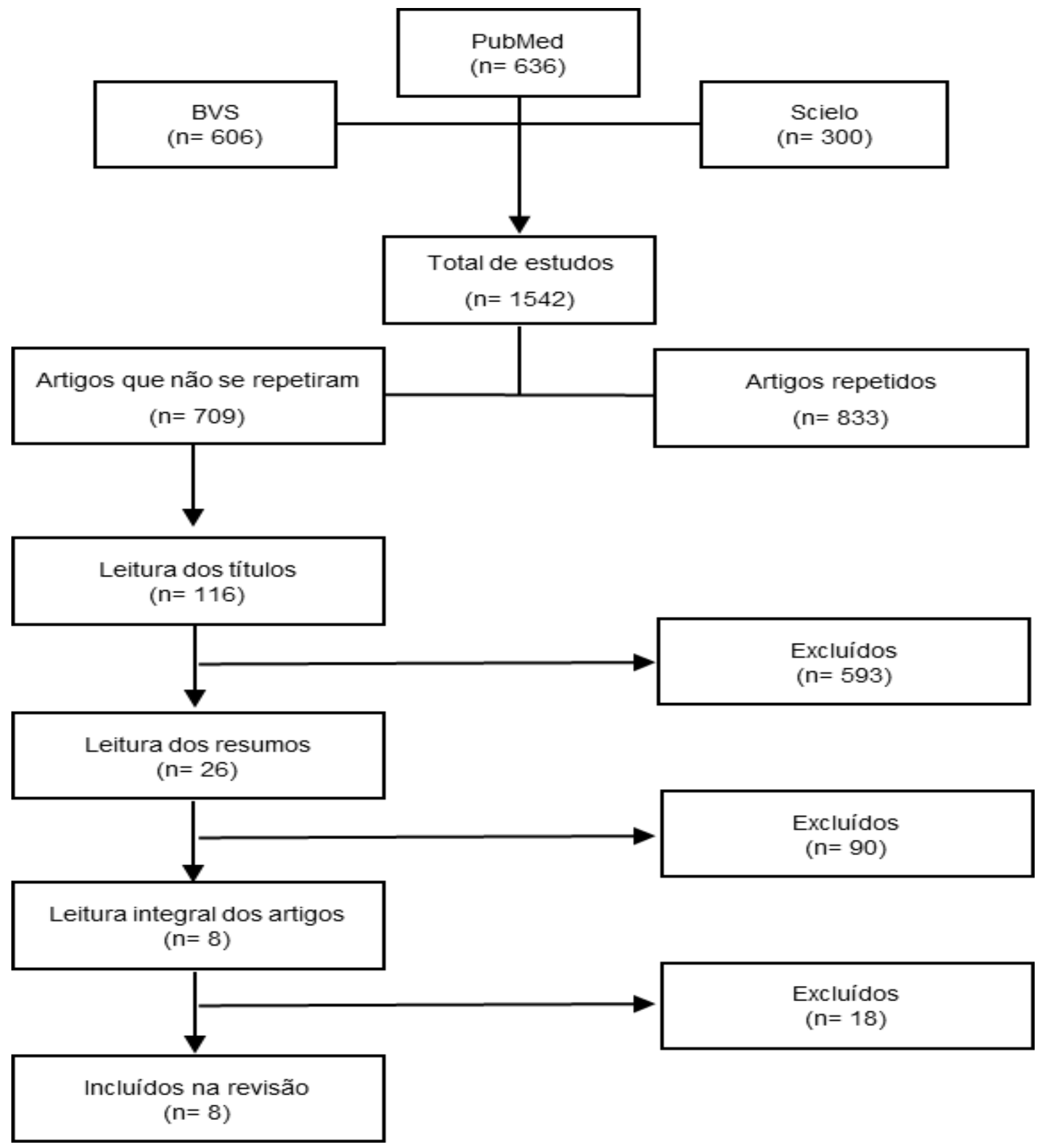

Fonte: Próprio autor, 2018.

\section{RESULTADOS}

A princípio foram encontrados 1542 artigos, dos quais foram selecionados 8, de acordo com a adequação dos mesmos aos critérios de inclusão citados anteriormente. Um total de 4 artigos selecionados nesta revisão, estudaram a influência da suplementação combinada das vitaminas $\mathrm{C}$ e E, sobre aspectos adaptativos do exercício físico e sua ação sobre a melhora do rendimento no treinamento de endurance. Porém, a ação dos micronutrientes sobre o metabolismo insulínico, peroxidação lipídica e recuperação pulmonar, também foram estudados. Os aspectos particulares de cada estudo tais como, autoria, efeitos estudados, delineamento da pesquisa, população, protocolo de suplementação e resultados obtidos, estão dispostos na Tabela 1. 
Tabela 1 - Estudos incluídos na presente revisão.

\begin{tabular}{|c|c|c|c|c|}
\hline $\begin{array}{c}\text { Autoria/A } \\
\text { no }\end{array}$ & Efeitos estudados & $\begin{array}{c}\text { Desenho do } \\
\text { estudo/ população }\end{array}$ & Protocolo de suplementação & Resultados encontrados \\
\hline $\begin{array}{l}\text { Ristow et } \\
\text { al., } 2009 .\end{array}$ & $\begin{array}{l}\text { Sensibilidade à insulina }(\mathrm{SI}) \\
\text { em indivíduos treinados e } \\
\text { não treinados. }\end{array}$ & $\begin{array}{l}\text { Caso-controle, } \\
\text { placebo controlado. } \\
\mathrm{N}=40, \mathrm{~S}=\mathrm{M}, \mathrm{IM}= \\
26,7 \text { anos. }\end{array}$ & $\begin{array}{l}\text { - Vitamina C }(1000 \mathrm{mg} / \mathrm{dia}) \quad+ \\
\text { Vitamina E }(400 \mathrm{mg} / \mathrm{dia}) \\
\text { - Placebo }\end{array}$ & 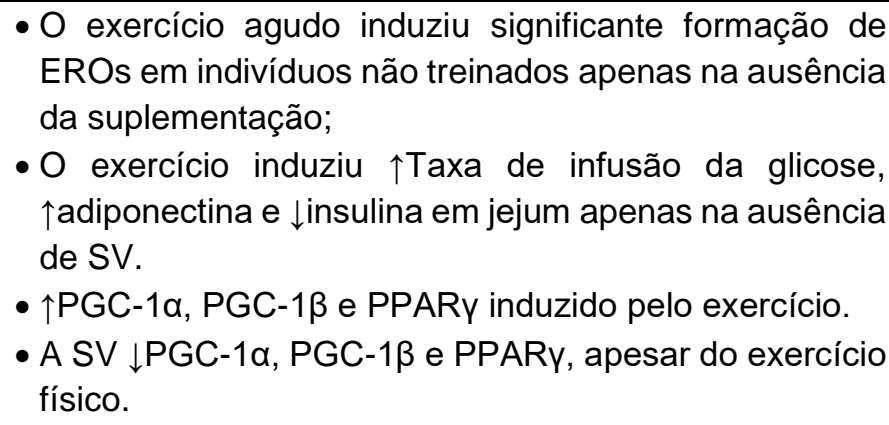 \\
\hline $\begin{array}{l}\text { Nazıroğlu } \\
\text { et al., } \\
2010 \text {. }\end{array}$ & $\begin{array}{l}\text { Peroxidação lipídica }(\mathrm{PL}) \text { e } \\
\text { nível de antioxidantes em } \\
\text { jogadores de basquete. }\end{array}$ & $\begin{array}{l}\text { Duplo-cego, placebo } \\
\text { controlado. } \mathrm{N}=14, \mathrm{~S}= \\
\mathrm{M}, \mathrm{IM}=16,8 \text { anos }\end{array}$ & $\begin{array}{l}\text { - Vitamina C (500 mg/dia })+ \text { Vitamina } \\
\text { E (150 mg/dia) } \\
\text { - Placebo }\end{array}$ & $\begin{array}{l}\text { - } \uparrow P L \text { no grupo placebo e } \downarrow P L \text { na SV. } \\
\text { - } \downarrow \text { Atividade da GSH-Px e } \downarrow G S H \text { no grupo placebo. } \\
\text { - } \uparrow \text { valores de GSH-Px e GSH após SV. } \\
\text { - } \uparrow[\text { ] plasmática das vitaminas A, C e E na SV. }\end{array}$ \\
\hline $\begin{array}{l}\text { Yfanti et } \\
\text { al., } 2010 .\end{array}$ & $\begin{array}{l}\text { Desempenho de indivíduos } \\
\text { saudáveis em diferentes } \\
\text { aspectos do treino de } \\
\text { resistência. }\end{array}$ & $\begin{array}{l}\text { Duplo-cego, placebo } \\
\text { controlado. } \mathrm{N}=21, \mathrm{~S}= \\
\mathrm{M}, \mathrm{IE}=18-40 \text { anos }\end{array}$ & $\begin{array}{l}\text { - Vitamina C (500 mg/dia })+ \text { Vitamina } \\
\text { E (400 ui/dia) } \\
\text { - Placebo }\end{array}$ & $\begin{array}{l}\text { - } \uparrow[\text { ] plasmática da vitamina } C \text { e E na SV. } \\
\text { - } \uparrow \mathrm{V}_{2 \max } \text { e } \uparrow P_{\max } \text { em ambos os grupos, em RE. } \\
\text { - } \uparrow \text { Limiar de lactação em ambos os grupos. } \\
\text { - } \uparrow[\text { ]glicogênio no músculo esquelético em ambos os } \\
\text { grupos } \\
\text { - } \uparrow \text { Citrato sintetase e } \uparrow \beta \text {-hidroxiacil-desidrogenase em } \\
\text { RE. }\end{array}$ \\
\hline $\begin{array}{l}\text { Kang et } \\
\text { al., } 2012 .\end{array}$ & $\begin{array}{l}\text { Capacidade de resistência } \\
\text { ao exercício. }\end{array}$ & $\begin{array}{l}\text { Duplo-cego, placebo } \\
\text { controlado. } \mathrm{N}=17, \mathrm{~S}= \\
\mathrm{M}, \mathrm{IE}=20-65 \text { anos }\end{array}$ & $\begin{array}{l}\text { - Vitamina C (800 mg/dia) + Vitamina } \\
\text { E (320 ui/dia) } \\
\text { - Oligonol } \circledast \text { (Extrato de lichya }) \\
\text { - Placebo }\end{array}$ & $\begin{array}{l}\text { - Sem diferenças significativas } \mathrm{VO}_{2 m a x} \text { entre os grupos. } \\
\text { - } \uparrow \text { resistência no teste de corrida submáxima apenas na } \\
\text { suplementação com Oligonol@. } \\
\text { - } \downarrow \mathrm{VO}_{\max } \text { na SV. } \\
\text { - Sem diferenças significativas para limiar de lactação, } \\
\text { radicais livres e lactato desidrogenase entre os grupos. }\end{array}$ \\
\hline
\end{tabular}




\begin{tabular}{|c|c|c|c|c|}
\hline $\begin{array}{l}\text { Yfanti et } \\
\text { al., } 2012 .\end{array}$ & $\begin{array}{l}\text { Expressão da IL-6 muscular } \\
\text { e sérica, antes e depois do } \\
\text { exercício de resistência de } \\
\text { alta intensidade. }\end{array}$ & $\begin{array}{l}\text { Duplo-cego, placebo } \\
\text { controlado. } \mathrm{N}=21, \mathrm{~S}= \\
\mathrm{M}, \mathrm{IM}=31 \text { anos }\end{array}$ & $\begin{array}{l}\text { - Vitamina C (500 mg/dia) + Vitamina } \\
\text { E (400 ui/dia) } \\
\text { - Placebo }\end{array}$ & $\begin{array}{l}\text { - } \uparrow \text { vitaminas C e E na SV. } \\
\text { - } \uparrow V O_{2 \max } \text { e } \uparrow P_{\max } \text { em ambos os grupos, em RE. } \\
\text { - } \downarrow \text { IL-6 no grupo placebo e } \uparrow \text { cortisol em RE em ambos os } \\
\text { grupos. } \\
\text { - } \downarrow \text { IL-6 mRNA nos grupos em RE. }\end{array}$ \\
\hline $\begin{array}{l}\text { Paulsen } \\
\text { et al., } \\
2014 \text {. }\end{array}$ & $\begin{array}{l}\text { Adaptação ao treino de } \\
\text { resistência. }\end{array}$ & $\begin{array}{l}\text { Duplo-cego, placebo } \\
\text { controlado. } N=54, \mathrm{~S}= \\
\mathrm{Fe} \mathrm{M}, \mathrm{IM}=25(\mathrm{~F}) \text { e } 26 \\
\text { anos }(\mathrm{M})\end{array}$ & $\begin{array}{l}\text { - Vitamina C }(250 \mathrm{mg} / \mathrm{dia})+\text { Vitamina } \\
\text { E ( } 58,5 \mathrm{mg} / \mathrm{dia}) \\
\text { - Placebo }\end{array}$ & $\begin{array}{l}\text { - } \uparrow[\text { ] plasmática da vitamina C e E na SV. } \\
\text { - } \uparrow O_{2 m a x} \text { e } \uparrow \text { desempenho no teste shuttle } 20 \text { m. } \\
\text { - } \uparrow \text { da expressão do gene COX4 e COX4 mRNA apenas } \\
\text { no grupo placebo. } \\
\text { - } \uparrow \text { PGC-1a no grupo placebo. } \\
\text { - } \downarrow \text { da expressão dos genes CDC42 e MAPK1 no grupo } \\
\text { placebo. }\end{array}$ \\
\hline $\begin{array}{l}\text { Kurti et } \\
\text { al., } 2016 .\end{array}$ & $\begin{array}{l}\text { Função das vias aéreas de } \\
\text { indivíduos com asma } \\
\text { induzida por exercício (AIE) }\end{array}$ & 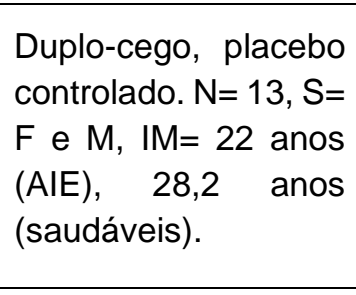 & $\begin{array}{l}\text { - Vitamina C (500 mg/dia })+ \text { Vitamina } \\
\text { E ( }(300 \text { ui/dia }) \\
\text { - Placebo }\end{array}$ & 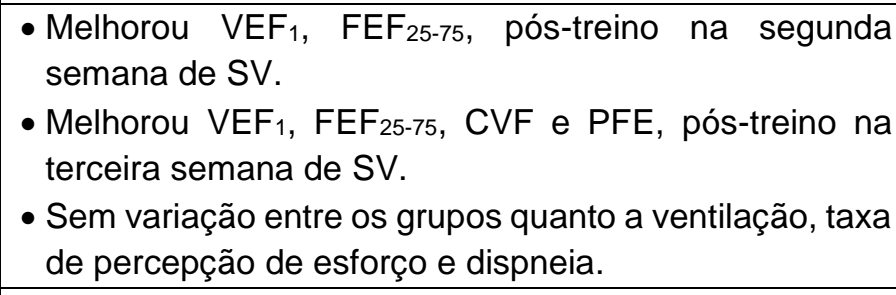 \\
\hline $\begin{array}{l}\text { Chou et } \\
\text { al., } 2018\end{array}$ & $\begin{array}{l}\text { Dano muscular, hemólise e } \\
\text { respostas inflamatórias em } \\
\text { atletas do Taekwondo. }\end{array}$ & $\begin{array}{l}\text { Duplo cego, placebo } \\
\text { controlado. } \mathrm{N}=18, \mathrm{~S}= \\
\mathrm{M}, \mathrm{IM}: 21,3 \text { anos. }\end{array}$ & $\begin{array}{l}\text { - Vitamina C } \quad(2000 \quad \mathrm{mg} / \mathrm{dia}) \quad+ \\
\text { Vitamina E (1400 ui/dia) } \\
\text { - Placebo }\end{array}$ & $\begin{array}{l}\text { - } \downarrow[] \text { mioglobina circulante e } \downarrow \text { creatina quinase na SV. } \\
\text { - } \downarrow \text { hemólise na SV } \\
\text { - } \downarrow \text { Razão plaqueta/linfócito na SV }\end{array}$ \\
\hline
\end{tabular}

Fonte: Próprio autor, 2018.

Legenda: $\mathrm{N}$ = número da população; $\mathrm{S}=$ sexo; $\mathrm{M}$ = sexo masculino; $\mathrm{F}=$ sexo feminino; $I M=$ Idade média; $\mathrm{IE}=$ intervalo etário; EROs= espécies reativas de oxigênio; PGC-1 $\alpha=$ coativador 1 -alfa de receptores ativados por proliferadores de peroxissoma gama; PGC-1 $\beta=$ coativador 1-beta de proliferadores de peroxissoma gama; $\mathrm{PPARY}=$ proliferador de peroxissoma ativado por receptor gama; $\mathrm{PL}=$ peroxidação lipídica; $\mathrm{SV}=$ suplementação de vitaminas; [ ]= concentração; GSH-Px: glutationa peroxidase; GSH: glutationa reduzida; $\mathrm{RE}=$ Resposta ao exercício; $\mathrm{VO}_{2 \max }=$ consumo máximo de oxigênio; $\mathrm{P}_{\max }=$ potência máxima; IL-6= interleucina 6; IL-6 mRNA= interleucina 6 micro RNA; COX4= COX4 micro RNA; AIE= asma induzida pelo exercício; $V_{E F}=$ volume expiratório forçado no primeiro segundo; $F E F_{25-75=}$ fluxo expiratório forçado entre $25 \%$ e $75 \%$; CVF= capacidade vital forçada; $P F E=$ pico do fluxo expiratório. 


\section{DISCUSSÃO}

A ingestão extra de vitaminas e minerais tem se tornado uma prática cada vez mais comum na realidade esportiva, devido à sua suposta ação antioxidante sobre a melhora do desempenho físico e fortalecimento da saúde. Fayh et al (2013), demonstraram que o consumo destes micronutrientes entre praticantes amadores de atividade física apareceu como o terceiro mais frequente (12,3\%), estando logo atrás dos suplementos proteicos $(38,9 \%)$ e calóricos $(21,3 \%)$. Resta saber se as alegações para tal consumo encontram amparo nas evidências científicas.

\section{Sensibilidade à insulina}

Sabe-se que o exercício físico aumenta a produção de EROs no músculo esquelético, que à princípio, seriam responsáveis por degenerar estruturas celulares e induzir o estresse oxidativo. Entretanto, não está bem estabelecido até que ponto os efeitos de promoção de saúde gerados pela prática, estão ligados a esta produção aumentada. No estudo de Ristow et al (2009), a carga oxidativa em decorrência ao exercício se elevou apenas na ausência da suplementação com antioxidantes. Outrossim, a ingestão dos antioxidantes inibiu a expressão de reguladores transcricionais envolvidos no metabolismo da glicose, como PCG-1a, PCG$1 \beta$ e receptor de peroxissoma-y (PPARy). Consequentemente, os resultados evidenciaram o crescimento significativo da taxa de infusão de glicose (TIG), adiponectina e decréscimo do nível de insulina de jejum apenas no público não suplementado com antioxidantes, independentemente do estado prévio de condicionamento físico, indicando o aumento da sensibilidade à insulina induzida pelo exercício somente na ausência de suplementação.

Os benefícios do exercício físico sobre aspectos da saúde humana, como a maior captação da glicose pelos músculos, diminuição da resistência e aumento da sensibilidade à insulina, envolve múltiplos mecanismos de ativação (MANKOWSKI, et al., 2015). Segundo Ristow et al (2009), apesar de a produção de EROs ser precursora do estresse oxidativo, a liberação destes compostos causada pelo exercício físico

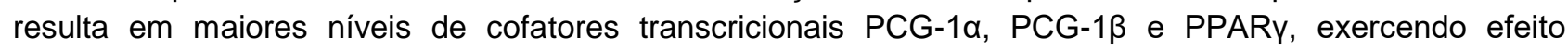
estratégico sobre a melhora da sensibilidade à insulina. Logo, a ingestão das vitaminas $C$ e $E$, por possuírem ação antioxidante, barrariam está cadeia adaptativa, anulando a promoção de sensibilidade à insulina (Figura 2).

\section{Peroxidação lipídica}

Como mencionado anteriormente, o exercício de alto rendimento, pode estimular a produção de radicais livres além do que o sistema antioxidante biológico é capaz de reprimir, ocasionando estresse oxidativo e inflamação. Esta sobreposição oxidativa é marcada pela perda de função de moléculas e instabilidade homeostática, gerando danos às estruturas celulares, teciduais, proteicas e até mesmo ao DNA. A peroxidação lipídica é a principal via de lesão, caracterizada pela degeneração da camada lipídica da membrana que envolve as células que gera desequilíbrio do balanço hídrico e oxidação de cofatores enzimáticos, nucleotídeos, DNA e compostos tióis. As enzimas glutationa peroxidase (GSH-Px) e a peroxidase reduzida (GSH) são importantes componentes do sistema antioxidante enzimático e utilizadas como marcadores de peroxidação lipídica (FILLAIRE, et al., 2011; PEDROSO, et al., 2015).

No estudo de Nazıroğlu et al (2010), a suplementação com as vitaminas C e E resultou em menor peroxidação lipídica no plasma e eritrócito, quando comparado à fase pré-suplementação e ao grupo placebo, além de maiores concentrações de GSH-Px e GSH em jogadores profissionais de basquete submetidos à treinamento de alta intensidade. Ademais, as concentrações das vitaminas $A, C$ e $E$ foram significativamente maiores no grupo suplementado com antioxidantes. Para os autores, a ingestão combinada destes nutrientes, exerceu efeito protetivo sobre o dano oxidativo causado pelo exercício. 
Figura 2. Ilustração do impacto do exercício sobre a sensibilidade à insulina e influência da suplementação com as vitaminas $\mathrm{C}$ e $\mathrm{E}$.

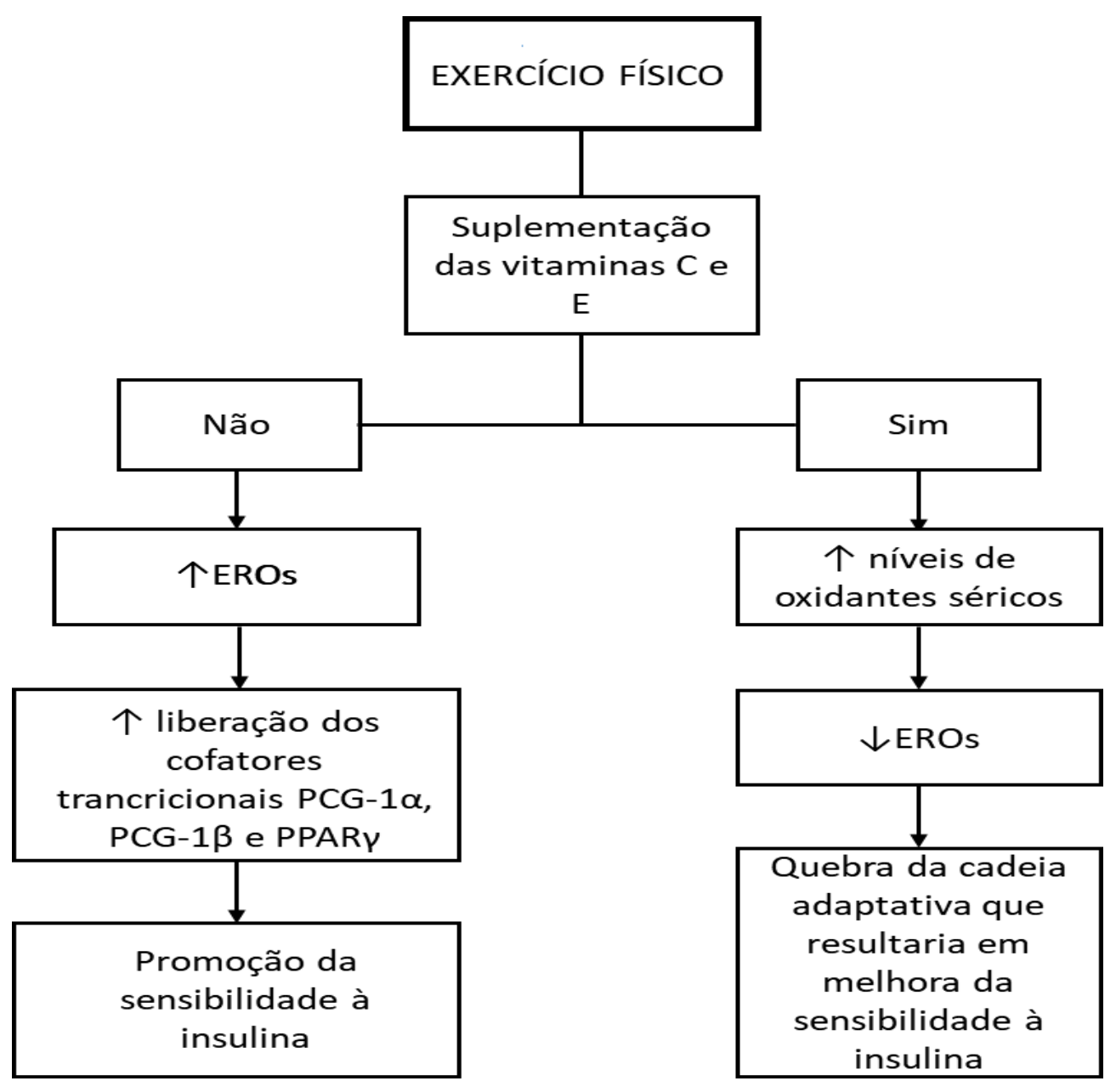

Fonte: Próprio autor, 2018; Ristow et al, 2009.

A ingestão combinada destas vitaminas tem sido a mais utilizada, com a alegação de prevenção do estresse oxidativo e até mesmo aumento da longevidade (WARKZYNIAK, et al., 2013; QATO, et al., 2008). O ácido ascórbico, é um micronutriente hidrossolúvel, citado como agente de grande potencial antioxidante. O a-tocoferol, por sua vez, mais comumente suplementada em forma de a-tocoferol, possui caráter lipossolúvel, tem sua ação relacionada à eliminação dos radicais lipídicos. Uma vez oxidado, o a-tocoferol pode ser transformado novamente em sua versão não oxidada por outro antioxidante, como o ácido ascórbico. Portanto, esse mecanismo impede que os radicais de vitamina $E$ se acumulem e induzam a peroxidação lipídica excessiva (VARDI, et al., 2013).

\section{Dano muscular, hemólise e resposta inflamatória}

O treinamento exaustivo impõe ao aparelho locomotor uma maior sobrecarga, podendo resultar em dano muscular e hemólise. A lesão ou dano muscular pode ocorrer em diferentes níveis de magnitude, conforme a variação de contração, principalmente em práticas que envolvem movimentos excêntricos. $O$ esgotamento físico resultante destas práticas, pode ocasionar na supressão de proteínas no músculo e resposta inflamatória em decorrência disso (FOSCHINI, et al., 2007; PEDROSO, et al., 2015).

Chou et al (2018), concluíram que a suplementação dos antioxidantes em curto prazo, diminuiu marcador de dano tecidual, hemólise e resposta inflamatória durante e após sucessivos combates de Taekwondo. O teste físico ocorreu por meio da simulação de uma competição desta modalidade de combate, onde os 
participantes competiriam entre si, em 4 lutas cada. Foram percebidos menores níveis de mioglobina, creatina quinase e hemólise, no grupo suplementado com as vitaminas. Além disso, os antioxidantes pareceram suprimir a hemólise de células vermelhas provocada durante a competição.

O exercício físico extenuante, principalmente em períodos de competição profissional, pode elevar de maneira acentuada, as micro lesões musculares e o estresse oxidativo. Durante a atividade intensa, a força excêntrica empregada na execução de movimentos, causa danos às fibras celulares e modifica o padrão de permeabilidade, permitindo que uma porção importante de enzimas e proteínas vazem, como a creatina quinase e a mioglobina. Ademais, a produção excessiva de EROs pode contribuir para os processos de dano do tecido muscular (CHIODO, et al., 2011). Semelhantemente, Peternelj e Coombes (2011), relataram em sua meta-análise, que a ingestão de antioxidantes está relacionada a melhor recuperação após competição e diminuição do dano muscular provocado pelo exercício extenuante.

A hemólise intravascular e a resposta inflamatória aguda, são resultantes de traumas físicos e do estresse oxidativo, que ocorrem em esportes que demandam movimentos excêntricos (ROBINSON, et al., 2006). Estudos não demonstram que a suplementação isolada da vitamina $E$ tenha ação protetiva sobre o dano oxidativo às células vermelhas do sangue provocado pelo exercício (AVERY, et al., 2003). Porém, Chou et al (2018) relataram que a atenuação da hemólise e inflamação encontrados, se deve à ação sinérgica da combinação dos dois antioxidantes.

\section{Resistência e performance}

Uma grande preocupação de praticantes amadores ou profissionais de atividade física é a melhora do desempenho, pois o estresse oxidativo gerado pelo exercício de alta intensidade, pode resultar em peroxidação lipídica e dano muscular, prejudicando a performance e dificultando a resistência na execução esportiva (SILVESTRE, et al., 2009). Em razão disso, a adição de suplementos à base de vitaminas antioxidantes na rotina destes indivíduos, visa também, suavizar estes efeitos. Entretanto, os estudos sobre esta temática não evidenciaram este benefício.

Para Yfanti et al (2010) a ingestão destes suplementos em indivíduos sem deficiência prévia destes nutrientes, não exerceu qualquer influência sobre a resposta adaptativa ao exercício extenuante de resistência, apesar de as dosagens administradas de ácido ascórbico e $\alpha$-tocoferol serem 5 e 15 vezes maiores que o recomendado para a dieta, respectivamente. Os resultados mostraram que, a potência máxima $\left(P_{\max }\right)$, consumo máximo de oxigênio $\left(\mathrm{VO}_{2 \max }\right)$ e limiar de lactação tiveram elevação acentuada independentemente da suplementação, provavelmente em resposta ao exercício. Do mesmo modo, as concentrações de enzimas mitocondriais, como o citrato sintetase e $\beta$-hidroxiacil-CoA desidrogenase, e nível de glicogênio, também foram significativamente maiores no tecido muscular em resposta ao treino físico. Não foram observadas diferenças metabólicas em comparação ao grupo placebo.

No caso de Kang et al (2012), optou-se por três tipos diferentes de suplementação, onde além das vitaminas e placebo, um grupo recebeu Oligonol $\AA$, que consiste em extrato seco de lichia (fruta), um concentrado de polifenóis e catequinas. O grupo que recebeu as vitaminas apresentou significante diminuição do $\mathrm{VO}_{2 \max }$, o que indica inibição da capacidade de endurance. Porém, a ingestão de Oligonol® resultou em melhora do desempenho nos testes de esteira, sem diminuição do $\mathrm{VO}_{2 \max }$, sugerindo um papel otimizador da resistência. $\mathrm{O}$ grupo Oligonol ${ }^{\circledR}$ apresentou menores níveis de lactado desidrogenase, enquanto no grupo vitaminas se percebeu uma elevação dos valores após o protocolo. Os autores concluíram que apesar de ambos os suplementos reduzirem os níveis de radicais livres no plasma, os efeitos sobre o treinamento de endurance foram diferentes, sendo que a administração como extrato de lichia pareceu melhorar a capacidade de resistência ao exercício, enquanto o mesmo efeito não foi observado com a ingestão das vitaminas $\mathrm{C}$ e $\mathrm{E}$.

Yfanti et al (2012), avaliaram a interação do consumo extra de micronutrientes antioxidantes com o nível de interleucina-6 (IL-6) antes e depois do treinamento de resistência de alta intensidade. A suplementação dos micronutrientes elevou os níveis de vitaminas $\mathrm{C}$ e $\mathrm{E}$ no sangue. A $\mathrm{P}_{\max }$ e o $\mathrm{VO}_{2 \max }$ se acentuaram em ambos os grupos, em razão do treinamento intensivo. O nível de IL-6 sérica estive diminuído antes do 
exercício, apenas no grupo suplementado com vitaminas, e elevados imediatamente após o exercício, sendo atenuados 12 semanas depois apenas no grupo placebo, possivelmente devido à adaptação corporal ao exercício de endurance. O exercício também mitigou a expressão da IL-6 mRNA no músculo esquelético, em ambos os grupos. Estes achados, indicam que a suplementação pode ter reduzido o efeito do exercício físico na modulação da resposta antioxidante e anti-inflamatória.

A pesquisa de Paulsen et al (2014) estudou papel da ingestão de micronutrientes na adaptação ao exercício de resistência. Os resultados sugeriram que os níveis das vitaminas $\mathrm{C}$ e $\mathrm{E}$ no plasma sanguíneo estavam aumentados no grupo suplementado com os antioxidantes. O aumento do $\mathrm{VO} 2_{\max }$ e melhora da performance no teste shuttle de 20 metros ocorreu em ambos os grupos, demonstrando que este fator tenha sido induzido pelo treinamento de resistência. Contudo, o PGC-1a, o marcador COX4, ativados pelo proliferador de peroxissoma cistólico, e os níveis de CDC42 mRNA e a proteína MAPK1, ativada por imunógeno, que estão envolvidos na biogênese mitocondrial, aumentaram apenas no tecido muscular do grupo placebo. Dados concordantes como estudo de Ristow et al (2009), onde o fator PGC-1a pareceu ter sido inibido pela ação dos antioxidantes administrados. Logo, a suplementação diária das vitaminas atenuou o nível de marcadores de síntese de mitocôndrias, sem influenciar os parâmetros de desempenho físico. Para os autores, a ingestão de antioxidantes associados ao exercício de resistência deve ser vista com cautela, pois o aumento da quantidade e qualidade funcional das mitocôndrias nos músculos esqueléticos, é uma das principais adaptações corporais ao exercício físico. A capacidade de resistência física está diretamente ligada ao conteúdo mitocondrial (PEREIRA, 2015).

Para a verificação da relação entre a suplementação dos antioxidantes estudados sobre e a melhora da performance no exercício, os testes $\mathrm{P}_{\max } \mathrm{e} \mathrm{VO}_{2 \max }$, foram os mais frequentemente relatados nos artigos aqui selecionados. Nas pesquisas de Yanti et al (2010) e Yfanti et al (2012), não foram percebidas diferenças entre os grupos suplemento e placebo sobre os testes de $P_{\max }$ e $\mathrm{VO}_{2 \max }$. A ingestão de vitaminas também não influenciou na melhora da $P_{\max }$ no estudo de Paulsen et al (2014). Por outro lado, Kang et al (2012) relataram resposta negativa deste consumo sobre a $P_{\max }$. Dados concordantes com Gomez-Cabrera et al (2015), que relatam que a suplementação de antioxidantes não afetou o $\mathrm{VO}_{2 \max }$.

\section{Asma induzida pelo exercício}

A asma induzida pelo exercício (AIE) é caracterizada pelo fechamento temporário das vias aéreas em razão do treinamento físico vigoroso, ocasionando na falta de ar, chiado no peito e tosse. A AIE está relacionada a diminuição do volume expiratório forçado no primeiro segundo (VEF 1 ), capacidade vital forçada (CVF), fluxo expiratório forçado em 50\% (FEF50) e entre $25 \%$ e 75\% (FEF25-75) da CVF, pico do fluxo expiratório (PFE) e a taxa de fluxo exploratória de pico (TFEP). Os mecanismos desencadeadores deste quadro não são totalmente explicados, mas algumas hipóteses sugerem a desidratação e resfriamento das vias aéreas durante a atividade, impulsionariam está dificuldade respiratória (LAITANO, MEYER, et al., 2007).

Segundo Kurti et al (2016) a ingestão combinada destes antioxidantes pode contribuir com a recuperação pulmonar de indivíduos com AIE. Neste estudo, percebeu-se a melhora progressiva e significativa de todos os parâmetros analisados ( $\mathrm{VEF}_{1}, \mathrm{CVF}, \mathrm{FEF}_{50}, \mathrm{FEF}_{25-75}$, PFE) no grupo que recebeu as vitaminas, no que diz respeito aos exames que precediam o teste físico. Quanto ao período pós-exercício, houve diminuição do $V_{E F}$ e TFEP comparado ao grupo placebo. Após as 3 semanas de suplementação com os antioxidantes, a função pulmonar melhorou significativamente.

Para os autores, possivelmente haveria uma relação entre a carga antioxidantes das vitaminas $\mathrm{C}$ e $\mathrm{E}$ e o metabolismo histamínico aumentado pela produção de EROs, causando alterações no mecanismo de estimulação direta de contração da musculatura lisa pulmonar. Logo, o aumento do status antioxidante pode ter reduzido os radicais livres e histamina que atuam no músculo liso pulmonar, aliviando a broncoaspiração. 


\section{CONCLUSÃO}

A suplementação das vitaminas C e E tiveram efeitos benéficos sobre a peroxidação lipídica, dano muscular, resposta inflamatória e hemólise, que são via de regra, decorrentes de elevações anormais da produção de EROs após exercício extenuante. A ingestão de antioxidantes também resultou na melhora do quadro de AIE. Entretanto, a formação de EROs resultante do metabolismo aeróbico ou anaeróbico, atua como importante regulador do sistema antioxidante natural, promovendo homeostase corporal, além de servir como via de sinalização de fatores transcripcionais envolvidos na resposta insulínica. Os suplementos nutricionais de vitaminas em questão, tem sido consumido entre atletas e praticantes amadores de atividade física, como recurso ergogênico, com vistas na melhora do desempenho, porém, o uso destes antioxidantes pode reduzir a concentração fisiológica destes agentes oxidativos, inibindo adaptações favoráveis do exercício.

\section{REFERÊNCIAS}

1. AVERY NG, KAISER JL, SHARMAN MJ et al. Effects of vitamin E supplementation on recovery from repeated bouts of resistance exercise. Journal of Strength Conditioning Research, 2003; 17(4): 801-809.

2. BENNEMAN GD, ZAVADSKI F, SCHIESSEL DL et al. Estratégias de alimentação, hidratação e suplementação, em período de treinamento e competição de triatletas no Ironman 140.6 e 70.3 Brasil. Revista Brasileira de Nutrição Esportiva, 2018; 12(70): 160-169.

3. BRASIL. Resolução CFN no 390/2006. Regulamenta a prescrição dietética de suplementos nutricionais pelo nutricionista e dá outras providências. Diário Oficial da União. 2006.

4. CAPRIO JM, MACHADO JPC, FRANCO GS et al. Perfil alimentar e antropométrico de um time de atletas de handebol da categoria junior. Revista Brasileira de Nutrição Esportiva, 2018; 12(70): 238-245.

5. CHIODO S, TESSITORE A, CORTIS C et al. Stress-related hormonal and psychological changes to official youth Taekwondo competitions. Scandinavian Journal of Medicine \& Science in Sports, 2011; 21(1): 111-119.

6. CHOU CC, SUNG YC, DAVISON G et al. Short-term high-dose vitamin C and E supplementation attenuates muscle damage and inflammatory responses to repeated Taekwondo competitions: a randomized placebocontrolled trial. International Jounal of Medical Sciences, 2018; 15(11): 1217-1226.

7. CONSELHO FEDERAL DE EDUCAÇÃO FÍSICA. Academias de ginástica: mercado em constante crescimento. Revista Educação Física, 2015; 58: 13.

8. CRUZAT V, ROGERO MM, BORGES MC et al. Aspectos atuais sobre estresse oxidativo, exercícios físicos e suplementação. Revista Brasileira de Medicina do Esporte, 2007; 13(5): 336-342.

9. FAYH APT, SILVA CV, JESUS FRD et al. Consumo de suplementos nutricionais por frequentadores de academias da cidade de Porto Alegre. Revista Brasileira de Ciências do Esporte, 2013; 35(1): 27-37.

10. FILLAIRE E, MASSART A, ROUVEIX $M$ et al. Effects of 6 weeks of $n-3$ fatty acids and antioxidant mixture on lipid peroxidation at rest and postexercise. European Journal of Applied Physiology, 2011; 111(8): 1829-1839.

11. FOSCHINI D, PRESTES J, CHARRO MA. Relação entre exercício ísico, dano muscular e dor muscular de início tardio. Revista Brasileira de Cineantropometria \& Desenvolvimento Humano, 2007; 9(1): 101-106.

12. GOMEZ-CABRERA MC, SALVADOR-PASCUAL A, CABO H et al. Redox modulation of mitochondriogenesis in exercise. Does antioxidant supplementation blunt the benefits of exercise training? Free Radical Biology \& Medicine, 2015; 86: 37-46.

13. HALLAK A, FABRINI S, PELUZIO MCG. Avaliação do consumo de suplementos nutricionais em academias da zona sul de Belo Horizonte, MG, Brasil. Revista Brasileira de Nutrição Esportiva, 2007; 3(7): 55-60.

14. INSTITUTE OF MEDICINE/FOOD AND NUTRITIONAL BOARD. Dietary reference intakes for vitamin C, vitamin E, Selenium, and Carotenoids. Washigton, DC: National Academies Press, 2000.

15. JEUKENDRUP AE. Periodized nutrition for athletes. Sports Medicine, 2017; 47(1): 51-63.

16. KANG SW, HAHN S, KIM J et al. Oligomerized lychee fruit extract (OLFE) and a mixture of vitamin C end vitamin $\mathrm{E}$ for endurance capacity in double blind randomized controlled trial. Journal of Clinical Biochemistry and Nutrition, 2012; 50(2): 106-113.

17. KURTI SP, MURPHY JD, ERGUSON CS et al. Improved lung function following dietary antioxidant supplementation in exercise-induced asthmatics. Respiratory Physiologiy \& Neurobiology, 2016; 220: 95-101.

18. LAITANO O, MEYER F. Asma induzida pelo exercício: aspectos atuais e recomendações. Revista Brasileira de Medicina do Esporte, 2007; 13(1): 1-12. 
19. MACHADO-MOREIRA CA, VIMIEIRO-GOMES AC, SILAMI-GARCIA E et al. Hidratação durante o exercício: a sede é suficiente? Revista Brasileira de Medicina do Esporte, 2006; 12(6): 405-409.

20. MANKOWSKI RT, ANTON SD, BUFORD TW et al. Dietary antioxidants as modifiers of physiologic adaptations to exercise. Medicine \& Science in Sports \& Exercise, 2015; 47(9): 1857-1868.

21. MATOS JB, LIBERALLI R. O uso de suplementos nutricionais entre atletas que participaram da segunda travessia da lagoa de Peri de 3.000m. Revista Brasileira de Nutrição Esportiva, 2008; 2(10): 185-197.

22. MENDES RR, TIRAPEGUI J. Introdução à Nutrição e à Atividade Física. In: TIRAPEGUI, J. Nutrição, Metabolismo e Suplementação na Atividade Física. 2 ed. São Paulo: Atheneu, 2012; 467 p.

23. NAZIROĞLU M, KILINÇ F, UĞUZ AC et al. Oral vitamin C and E combination modulates blood lipid peroxidation and antioxidante vitamin levels in maximal exercising basketball players. Cell Biochemistry and function, 2010; 28(4): 3000-3005.

24. PAULSEN G, CUMMING KT, HOLDEN G et al. Vitamin C and E supplementation hampers cellular adaptation to endurance training in humans: a double-blind, randomised, controlled trial. The Journal of Physiology, 2014; 592(8): 1887-1901.

25. PEDROSO CO, VICENZI K, ZANETTE C. Efeitos do estresse oxidativo e o uso da suplementação entre atletas. Revista Brasileira de Nutrição Esportiva, 2015; 9(53): 480-490.

26. PEREIRA B. Biogênese mitocondrial e exercício físico: hipótese do acoplamento elétrico-transcripcional. Revista Brasileira de Educação Física e Esporte, 2015; 29(4): 687-703.

27. PETERNELJ TT, COOMBES JS. Antioxidant supplementation durins exercise training: beneficial or demetrial? Sports Medicine, 2012; 41(12): 10443-1069.

28. RISTOW M, ZARSE K, OBERBACH A et al. Antioxidants prevent health-promoting effects of physical exercise in humans. Proceedings of the National Academy of Sciences of the United States of America, 2009; 21: 86658670.

29. ROBINSON Y, CRISTANCHO E, BÖNING D. Intravascular hemolysis and mean red blood cell age in athletes. Medicine \& Science in Sports \& Exercise, 2006; 38(3): 480-483.

30. SILVESTRE MGP, VILHENA RN, PEPELIASCOV IL et al. Vitamina C como agente antioxidante em exercício de endurance. Revista Brasileira de Nutrição Esportiva, 2009; 3(16): 313-318.

31. SOUZA IR, CARGNIN-CARVALHO A. Consumo de suplementos nutricionais nas academias da cidade de Braço do Norte-SC. Revista Brasileira de Nutrição Esportiva, 2018; 12(70): 213-221.

32. QATO DM, ALEXANDER GC, CONTI RM et al. Use of prescription and over-the-counter medications and dietary supplements among older adults in the United States. Journal of American Medical Association, v. 300, n. 24, p. 2867-2878, 2008.

33. VARDI M, LEVY NS, LEVY AP. Vitamin E in the prevention of cardiovascular disease: the importance of proper patient selection. The Journal of Lipid Research, 2013; 54(9): 2307-2314.

34. VIEBIG RF, NACIF MAL. Nutrição aplicada à atividade física e ao esporte. In: SILVA, S. M. C.; MURA, J. D. A. P. Tratado de alimentação, nutrição e dietoterapia. 2nd ed. São Paulo: Roca, 2010; 1338 p.

35. WAWRZYNIAK A, GORNICKA M, HAMULKA $J$ et al. $\alpha$-Tocopherol, ascorbic acid, and beta-carotene protect against oxidative stress but reveal no direct influence on p53 expression in rats subjected to stress. Nutrition Research, 2013; 33(10): 868-875.

36. YFANTI C, AKERSTRÖN T, NIELSEN S et al. Antioxidant supplementation does not alter endurance training adaptation. Medicine \& Science in Sports \& Exercise, 2010; 42(7): 1388-1395.

37. YFANTI C, FISCHER CP, NIELSEN S et al. Role of vitamin C supplementation on IL-6 in response to training. Journal of Applied Physiology, 2012; 112(6): 990-1000. 